\title{
RESISTÊNCIA DO Rhipicephalus (Boophilus) microplus AOS CARRAPATICIDAS: REVISÃO DE LITERATURA
}

\author{
FIDELIS JUNIOR, Otávio Luiz ${ }^{1}$ \\ SAMPAIO, Paulo Henrique ${ }^{2}$ \\ TEIXEIRA, Pedro Paulo Maia ${ }^{3}$ \\ ANDRÉ, Marcos Rogério ${ }^{4}$ \\ CADIOLI, Fabiano Antonio 5
}

\begin{abstract}
RESUMO: O carrapato Rhipicephalus (Boophilus) microplus é o principal ectoparasito de bovinos e esta associado à transmissão de doenças, causando grandes prejuízos econômicos a indústria da pecuária no geral. O surgimento de populações de carrapatos $R .(B)$ microplus resistentes aos carrapaticidas comerciais é um problema observado em muitas propriedades rurais no mundo, gerando um prejuízo de aproximadamente US\$ 7 bilhões por ano. O uso correto dos princípios ativos carrapaticidas existentes e conhecimento das diversas formas de resistência do $R$. (B) microplus a estes princípios são de grande valia para prevenir ou então diagnosticar precocemente o aparecimento da resistência nas diversas populações deste ectoparasita.
\end{abstract}

Palavras-chave: Carrapato. Ectoparasiticidas. Resistência

\section{RESISTANCE OF Rhipicephalus (Boophilus) microplus TO ACARICIDES}

SUMMARY: The Rhipicephalus (Boophilus) microplus is the main bovine ectoparasite and it is associated to a several diseases, causing economic losses to dairy and beef industry. The arose of commercial acaricides resistant population of $R$. microplus is a problem in many farms worldwide, causing US\$ 7 billion losses each year. The properly use of each acaricide active ingredient and, the knowledge of many forms of $R$. microplus' resistance to these drugs are very useful to prevent or for early diagnosis of the onset of resistance in ectoparasite population.

Keywords: Tick. Ectoparasiticides. Resistance

\section{INTRODUÇÃO}

O carrapato Rhipicephalus (Boophilus) microplus é o principal ectoparasito de bovinos, sendo responsável por grandes prejuízos na bovinocultura. Além da perda de sangue, transmissão de doenças como babesiose e anaplasmose, danos ao couro e causa de stress aos animais, o que

\footnotetext{
${ }^{1}$ Mestrando da Universidade Estadual Paulista Júlio de Mesquita Filho otaluf@ hotmail.com

2 Doutorando na área de Clínica Médica Veterinária na UNESP - Jaboticabal. Faculdade de Ciências Agrárias e Veterinárias, UNESP - câmpus de Jaboticabal paulohsampa@yahoo.com.br

${ }^{3}$ Doutor em Medicina Veterinária (Reprodução Animal). Prof. Dep. de Medicina Veterinária da Universidade Estadual do Centro-Oeste (PR), p_paulomt@yahoo.com.br

${ }^{4} \mathrm{PhD}$ em Medicina Veterinária (área de concentração Medicina Veterinária Preventiva). Prof. Assistente na Faculdade de Ciências Agrárias e Veterinárias (UNESP Jaboticabal. marcos_andre@fcav.unesp.br

${ }^{5}$ Graduado em Medicina Veterinária pela FCAV/Unesp (1996), residência em Clínica Médica de Grandes Animais junto ao Programa de Residência do HV \&quot;Laudo Natel\&quot;/FCAV/Unesp (1997 e 1998), mestrado (2001) e Doutor em Medicina Veterinária (Clínica Médica). Prof. Assistente FMV/Unesp - Campus de Araçatuba. $\underline{\text { fabianocadioli@fmva.unesp.br }}$
} 
mais preocupa atualmente é a rapidez no aparecimento da resistência desenvolvida pelos carrapatos aos produtos químicos utilizados para seu controle (MENDES et al., 2008).

O estabelecimento da resistência não ocorre apenas devido ao uso constante do carrapaticida, mas também ao manejo incorreto empregado para o controle do carrapato. Entre os fatores relacionados ao manejo que podem favorecer o rápido desenvolvimento da resistência, destacam-se o intervalo entre os tratamentos carrapaticidas, a aplicação incorreta do produto e o desconhecimento, por parte dos produtores, a respeito do ciclo do carrapato e dos grupos de carrapaticidas utilizados (ROCHA et al., 2006).

O conhecimento das boas práticas de manejo, adotadas no controle do carrapato dos bovinos, é importante para auxiliar o desenvolvimento de programas que visem prevenir o aparecimento da resistência, tendo como base o uso prudente dos carrapaticidas e o emprego de estratégias próprias para cada fazenda (MENDES et al., 2008).

\section{O CARRAPATO RHIPICEPHALUS (BOOPHILUS) MICROPLUS}

O R. microplus é um ectoparasita hematófago, que se distribui desde a latitude $40^{\circ}$ Norte a $30^{\circ} \mathrm{Sul}$, exceto nos Estados Unidos onde foi erradicado, ou em regiões muito áridas; ingere cerca de 0,5 a $3 \mathrm{~mL}$ de sangue ao longo de sua vida. Cada fêmea desse carrapato é capaz de produzir entre dois a três mil ovos (CARVALHO NETA; COSTA JUNIOR, 2007).

O parasitismo dos bovinos pelo carrapato $R$. microplus é uma das principais causas de perdas econômicas na pecuária, sendo responsável por prejuízos de 1 bilhão de dólares ao ano na América Latina e 7 bilhões de dólares no mundo, estimado pela FAO em 2004. Este carrapato causa perdas de grande vulto à pecuária brasileira (está presente em cerca de $96 \%$ dos municípios brasileiros) e à de outros países do mundo, atingindo cerca de $75 \%$ da população bovina mundial (SOUTELLO et al., 2002).

O R. microplus pertence à família Ixodidae, caracterizados principalmente por apresentarem escudo dorsal, com nítido dimorfismo sexual. Bovinos e equinos são os hospedeiros principais, mas cervídeos e pequenos ruminantes domésticos também podem ser atacados (BOWMAN, 2006). É um ectoparasita monoxeno, ou seja, um único hospedeiro é exigido para a sua evolução, apresentando duas fases no seu ciclo biológico: uma fase de vida livre e uma parasitária. Aproximadamente $95 \%$ da população está na vegetação, em fase de vida livre, na qual estão fêmeas ingurgitadas em postura, ovos em incubação e larvas esperando o hospedeiro; os outros $5 \%$ estão parasitando os bovinos, na forma de larvas, ninfas e adultos. Os sítios de predileção no hospedeiro são a região ventral do corpo, pescoço e peito do animal até a 
genitália, sendo que carrapatos imaturos podem ser encontrados nos ouvidos (NETO; TOLEDOPINTO, 2006).

A maioria dos estudos e tecnologias contra o R. microplus está direcionada para esses $5 \%$, por ser este o estágio que causa os prejuízos diretos (espoliação sanguínea e suas consequências) e indiretos (Complexo Tristeza Parasitária Bovina) aos bovinos (NETO; TOLEDO-PINTO, 2006).

\section{DESENVOLVIMENTO DE RESISTÊNCIA}

Existem dois mecanismos que conferem resistência aos carrapatos: mecanismos comportamentais e fisiológicos. Pouco se sabe sobre o mecanismo comportamental. Os mecanismos fisiológicos relacionados à resistência englobam a diminuição da penetração cuticular da droga, resistência metabólica e insensibilidade do local de ação da droga (KLAFKE, 2008).

A partir de um ponto de vista dos mecanismos envolvidos, a resistência aos piretróides tem sido caracterizada em maior grau do que em qualquer outra classe de acaricida. Embora uma grande quantidade de pesquisas tenha sido direcionada para a descoberta de mecanismos que causem a resistência aos organofosforados, muito pouco é conhecido ao nível molecular, e essa resistência parece ser mantida por intermédio de um processo multifatorial e complexo. Os mecanismos de resistência para os demais acaricidas são bem menos compreendidos. Os alvos de ação do fipronil e das lactonas macrocíclicas são conhecidos, e os estudos dos mecanismos de ação envolvidos estão ainda em estágios iniciais. O alvo de ação do amitraz ainda não foi definitivamente identificado, e isso é limitante aos estudos dos mecanismos envolvidos na resistência a esse acaricida (GUERREIRO et al., 2012)

A diminuição da penetração cuticular da droga faz com que as concentrações da mesma, no organismo do carrapato, não chegue a um patamar que a torne letal. Já a resistência metabólica é caracterizada por um aumento na capacidade que os indivíduos resistentes possuem de detoxificar ou eliminar o carrapaticida usado no tratamento. Isso pode ocorrer tanto pelo aumento da especificidade de enzimas responsáveis pelo metabolismo da droga, como pela superexpressão destas. Assim, as enzimas acabando agindo diretamente sobre o carrapaticida, fazendo com que a concentração do mesmo no carrapato seja abaixo da letal, evitando desta forma a morte do parasito, ou então, aumentando suas concentrações séricas, o que acelerariam o ritmo de detoxificação da droga no organismo do carrapato. A resistência por insensibilidade do sítio de ação caracteriza-se por uma mutação de um nucleotídeo na região codificadora de um gene, 
alterando a conformação estrutural de um receptor (Chave - fechadura). Essa alteração estrutural pode reduzir ou bloquear a habilidade da droga se ligar ao sítio de ação (KLAFKE, 2008).

Os alelos que conferem a resistência genética dos carrapatos aos carrapaticidas são raros, cerca de um a cada milhão de indivíduos, sendo assim a maior parte da população é composta por indivíduos suscetíveis. Quando um determinado princípio ativo é usado à população resistente a ele sobrevive, dando origem a uma nova geração de carrapatos agora também resistentes. À medida que novas aplicações deste produto vão sendo feitas, a população de suscetíveis vai diminuindo e a de resistentes vai crescendo (KLAFKE, 2008). Com o uso contínuo do produto, há o aumento de indivíduos com essa característica de resistência, uma vez que morrem os sensíveis, não resistentes, e os resistentes acasalam entre si, produzindo descendentes resistentes; é a chamada propagação do alelo resistente por pressão de seleção (FURLONG; MARTINS, 2000).

\section{RESISTÊNCIA A ORGANOFOSFORADOS}

Os organofosforados são compostos orgânicos derivados do ácido fosfórico (SARTOR; BICUDO, 1999) e compreendem um grupo grande e diverso de substâncias químicas com propriedades inseticidas, acaricidas e helminticidas. Alguns compostos organofosforados também possuem propriedades herbicidas ou fungicidas (BLAGBURN; LINDSAY, 2003).

Estes compostos atuam principalmente ligando-se e inibindo a acetilcolinesterase (AChE), enzima amplamente distribuída nos nervos, músculos e no fluido e elementos do sangue. Sua função é regular a neurotransmissão nas sinapses destruindo o neurotransmissor acetilcolina (ACh). A AChE termina a atividade da ACh hidrolisando-a na fenda sináptica. A inibição ocorre porque o composto organofosforado mimetiza a estrutura da ACh. A ligação da AChE e organofosforados resulta na transfosforilação da enzima (BLAGBURN; LINDSAY, 2003). Este processo resulta no acúmulo de ACh nos locais onde este neurotransmissor é liberado, promovendo hiperexcitabilidade e hiperatividade no parasita, seguindo-se incoordenação muscular e morte. (SARTOR; BICUDO, 1999).

No Brasil a resistência a organofosforados foi notada inicialmente em 1963, no Rio Grande do Sul (RS), sendo este o primeiro caso de resistência a esses compostos relatado na América do Sul. (WHARTON; ROULSTON, 1977).

Neste grupo, a resistência do carrapato está relacionada normalmente a um único gene semidominante, ou seja, os indivíduos heterozigotos também apresentam resistência, embora de menor amplitude do que os homozigotos resistentes. Os mecanismos da resistência aos organofosforados ainda precisam ser melhores elucidados, mas sabe-se que existe relação com a 
insensibilidade da acetilcolinesterase (FOIL et al., 2004), com o aumento do metabolismo das esterases localizadas no intertegumento de teleóginas resistentes e com a superexpressão dessas enzimas em larvas (VILLARINO et al., 2001). Li et al. (2003) citam ainda a participação da enzima citocromo P450 no processo de resistência do $R$. microplus a este composto.

Alguns trabalhos realizados na Argentina constataram que dentre os diferentes estágios de crescimento, a fase de metaninfa possui maior resistência aos organofosforados (MERLINI; YAMAMURA, 1999). Já Baffi (2006), detectou esterases estágio-específicas, sendo que os estágio de larva e ninfa de primeiro estádio mostraram maior atividade esterásica durante todo o desenvolvimento.

\section{RESISTÊNCIA A PIRETRÓIDES}

O primeiro piretróide foi sintetizado por Green Shchter e La Forje em 1949, por meio de uma modificação da cadeia lateral do álcool ciclopentenolone da piretrina I. A maioria dos piretróides deriva do ácido ciclopropanocarboxílico, com algumas exceções. Os piretróides sintéticos são solúveis na maioria dos solventes orgânicos, biodegradáveis e têm a vantagem de serem estáveis quando expostos ao ar e à luz (SARTOR; BICUDO, 1999).

Estes compostos são classificados em dois tipos: tipo I e tipo II. Os tipo I não possuem o grupamento $\alpha$-ciano (grupamento este responsável por determinar diferentes níveis de toxicidade ao composto), os quais são utilizados em ambientes domésticos, sob forma de spray. Já os tipo II possuem o grupamento $\alpha$-ciano, e são utilizados como ectoparasiticidas para animais (SARTOR; BICUDO, 1999).

Os piretróides exercem seus efeitos primariamente modulando a cinética de abertura dos canais de sódio nos nervos. Esta ação resulta em descargas repetitivas ou na despolarização da membrana e subsequente morte do artrópode-alvo. Pesquisas recentes também indicam que os inseticidas piretróides suprimem os complexos ácido $\gamma$-aminobutírico (GABA), receptores de glutamato e canais de $\mathrm{Ca}^{2+}$ ativados por voltagem (BLAGBURN; LINDSAY, 2003).

Foram identificados dois padrões de resistência para este grupo: o primeiro por insensibilidade do sítio de ação da droga, através de uma alteração do sítio de ação das esterases, tornando-os insensíveis por mutações do gene relacionados aos canais de sódio; a proteína codificada por esse gene altera sua estrutura, o que o torna resistente ao piretroide (HE et al., 1999; LI et al., 2008; CHEN et al., 2009); o segundo mecanismo, menos entendido, envolve a resistência metabólica, através da detoxificação da droga mediada pela ação de esterases e de citocromo P450 (MILLER et al., 1999). Entretanto em um estudo realizado por Crampton et al. (1999), mesmo após o bloqueio da enzima citocromo P450, amostras de carrapatos resistentes aos 
piretróides continuaram vivas após exposição ao agente, indicando que esta estrutura não possui grande relevância na degradação do composto.

\section{RESISTENNCIA A FORMAMIDINAS}

O amitraz é a única formamidina ectoparasiticida atualmente utilizada na Medicina Veterinária (BLAGBURN; LINDSAY, 2003). O amitraz possui amplo espectro, com excelente ação sobre artrópodes, exceto contra a mosca Haematobia irritans (SARTOR; BICUDO, 2006).

O mecanismo de ação deste fármaco ainda não foi totalmente esclarecido. Observou-se que penetra rapidamente em larvas de carrapato, inibindo a monoaminoxidase (MAO). Esta enzima mitocondrial possui ação catalisadora no processo de desaminação de catecolaminas, resultando em aumento dos níveis de noradrenalina e serotonina no sistema nervoso central do parasito. Há evidências da atuação deste produto nos canais de sódio da membrana nervosa do carrapato, inibindo a síntese de prostaglandinas, além de ser um agonista em receptores $\alpha$ adrenérgicos (SARTOR; BICUDO, 2006).

Nas teleógenas as formamidinas inibem o processo de liberação de ovos, impedindo a contração da musculatura responsável pela oviposição (SARTOR; BICUDO, 2006). Embora amplamente utilizado em várias regiões do mundo, o amitraz, no mercado há cerca de 20 anos, apresenta baixa ocorrência de resistência, que pode ser explicada pela característica de herança semidominante ou pelo fato de amostras resistentes terem um menor desempenho biológico (KLAFKE, 2008).

Assim como seu mecanismo de ação, o mecanismo de resistência ao amitraz ainda não está completamente elucidado. Sabe-se apenas que algumas populações de $R$. microplus resistentes apresentam aumento de atividade enzimática de esterases e glutationa-S-transferases (LI et al., 2004); ainda segundo esses autores, o provável mecanismo de resistência ao amitraz seja a insensibilidade do sítio de ligação, presumivelmente o receptor de octopamina. FragozoSanchez et al. (2011) sugeriram que a resistência ao amitraz é controlado por uma herança recessiva, também parece que há mais de um gene envolvido neste processo.

\section{RESISTÊNCIA A LACTONAS MACROCÍCLICAS}

As lactonas macrocíclicas são um grupo de drogas com ação endo e ectoparasiticida, especificamente para nematóides e artrópodes. São produtos de fermentação ou derivados de fungos habitantes do solo, do gênero Streptomyces. Além de possuírem atividade de amplo espectro, são eficazes em concentrações muito baixas (BLAGBURN; LINDSAY, 2003). 
O mecanismo de ação das lactonas macrocíclicas é potencializar a ação inibidora neuronal mediada pelo GABA, promovendo hiperpolarização neuronal do parasito e, portanto, inibindo a transmissão nervosa. Em insetos demonstrou-se também a ação desses compostos em canais de cloro GABA independentes onde há aumento na condutância da membrana do músculo, pelo bloqueio para a resposta do ácido ibotênico, que é um ativador específico do portão-glutamato, comumente encontrado no inseto. Como consequência, há um aumento da permeabilidade da membrana aos íons cloro, resultando em redução da resistência da membrana celular. Desta forma, essas moléculas provocam ataxia e paralisia nos insetos e nematódeos (SARTOR; BICUDO, 2006).

Gonzales et al. (1993) avaliaram a eficácia da doramectina contra infestações experimentais em bovinos por R. microplus. Foi observado que a eficácia terapêutica foi de $51 \%$ no dia um pós-tratamento (PT), 96\% no dia 3 PT e nos dias 4-7 dias PT foi de 99\%. Marques et. al. (1995), trabalhando na avaliação do efeito da ivermectina a $1 \%$, solução injetável, no tratamento de bovinos naturalmente infestados pelo R. microplus, observaram que no dia 8 PT a eficiência foi de $100 \%$, até o dia 29 PT a eficácia foi aproximadamente 99\%, e no dia 36 PT foi de $80,1 \%$.

\section{RESISTÊNCIA A FENILPIRAZÓIS}

O principal representante dessa classe de acaricidas é o Fipronil, sendo este um inseticida relativamente novo no mundo em desenvolvido pela empresa Rhone-Poulenc AG (Research Triangle Park, NC) (COLLINS; CALLCOTT, 1998).

O mecanismo de ação deste fármaco ocorre de duas maneiras: pela inibição dos canais de cloro ativados por GABA (COLE et al., 1993), ligando-se aos canais de cloro e, consequentemente, inibindo o fluxo de íons para dentro da célula nervosa resultando em hiperexcitação do sistema nervoso (RAUH et al., 1990); outra forma de ação ocorre sobre os canais ativados por glutamato, que existem especificamente em invertebrados, mas não em mamíferos (ZHAO et al., 2004).

Em um estudo realizado por Brito et al. (2010) o grupo fenilpirazol apresentou alta eficiência no combate aos carrapatos, com uma eficácia média de 99,9\%. Guerreiro et. al. (2012), relatam que a atividade em dois sítios de ação desempenha um papel fundamental em retardar ou prevenir a formação de altos níveis de resistência a esta droga. Ainda segunda os mesmos autores, são escassos os relatos da resistência ao fipronil em amostras de campo, ocorrendo descrição de casos apenas no Uruguai e Brasil, mas estudos sobre os mecanismos não foram relatados. 


\section{DIAGNÓSTICO DE RESISTÊNCIA AOS CARRAPATICIDAS}

O diagnóstico de resistência a carrapaticidas é necessário para identificar o problema, elaborar estratégias para o controle da situação, adotar táticas efetivas na prevenção da emergência de resistência, prevenir a disseminação de carrapatos e economizar fundos. Atualmente este procedimento é realizado por bioensaios in vitro ou in vivo. Os bioensaios in vitro são feitos com larvas ou teleógenas prontas para oviposição, já os bioensaios in vivo são utilizados animais naturalmente ou artificialmente infestados, que são submetidos ao tratamento com a droga testada (KLAFKE, 2008).

Para a realização do teste de sensibilidade dos carrapatos aos carrapaticidas, denominado de biocarrapaticidograma, é necessária a coleta de aproximadamente 200 fêmeas ingurgitadas, de dois ou três animais, que devem estar sem tratamento de carrapaticida por pelo menos 25 dias (se o tratamento utilizado anteriormente for banho de aspersão) ou 35 dias (se o tratamento utilizado anteriormente for injetável ou aplicação na linha do dorso). Este cuidado deve ser tomado para que não haja interferência de outros produtos no teste (FURLONG; PRATA, 2006).

Os parasitas coletados devem ser enviados em ate 48 horas para o laboratório, devidamente acondicionados (FURLONG; PRATA, 2006). No laboratório as teleógenas são submetidas a testes in vitro frente aos principais carrapaticidas disponíveis no mercado. No teste, grupos de $5 \mathrm{~g}$ de teleógenas são expostas durante 5 minutos a diferentes carrapaticidas nas concentrações recomendadas pelos fabricantes e posteriormente são incubadas a $27^{\circ} \mathrm{C}$ e Umidade Relativa (UR) de $80 \%$ por um período de 2 semanas. Após este tempo, as massas de ovos são separadas e mensuradas, continuando-se a observação. A produção de ovos e a eclosão dos mesmos são comparadas com um grupo controle (MARTINS, 2004). Os resultados desse teste demoram 35 a 40 dias (FURLONG; PRATA, 2006).

As larvas de carrapatos podem ser testadas através do Teste de Pacote com Larvas (TPL) ou pelo Teste de Imersão com Larvas (TIL). Os resultados das duas técnicas são obtidos através da porcentagem de larvas que morrem por causa do tratamento, comparada com a mortalidade de larvas de uma população sabidamente sensível ao principio ativo testado (KLAFKE, 2008).

As larvas são obtidas de teleógenas de $R$. microplus coletadas a campo. Estas são mantidas em estufa biológica a $27^{\circ} \mathrm{C}$ e UR superior a $80 \%$. No décimo dia de postura, os ovos são transferidos para tubos de ensaio para que ocorra a eclosão das larvas. Aproximadamente 70 a 100 larvas com idade entre 14 e 21 dias são removidas do tubo, com auxílio de um pincel e colocadas no papel filtro Whatman número 1 impregnado com o carrapaticida a ser testado, diluído em óleo de oliva e clorofórmio. O controle é feito com papeis filtro impregnados apenas 
com óleo de oliva e clorofórmio. Os envelopes são devidamente etiquetados e lacrados e são mantidos em estufa a $27^{\circ} \mathrm{C}$ e $85 \%$ de umidade por 24 horas. Após esse tempo é feita a contagem de larvas vivas e mortas (MENDES et al., 2007).

Técnicas mais novas como diagnósticos moleculares estão sendo aprimoradas para detectar possíveis populações resistentes de carrapatos a determinados acaricidas. Este tipo de análise não sofre interferência de fatores ambientais, que podem interferir em resultados de um bioensaio (KLAFKE, 2008).

\section{CONCLUSÃO}

O surgimento de populações de carrapatos $R$. microplus resistentes aos carrapaticidas comerciais é um problema observado em muitas propriedades rurais no mundo, inclusive no Brasil, gerando um prejuízo de US\$ 7 bilhões no mundo. Entretanto, os produtos carrapaticidas ainda são a melhor opção para o controle de populações de carrapatos. A escolha e o uso correto dos princípios ativos são importantes fatores que determinam a ocorrência de populações de $R$. microplus resistentes.

Além disso, devem ser observadas as concentrações e a dose por animal corretas. Quanto à frequência de aplicação, o ideal seriam banhos estratégicos a cada 21 dias ou a aplicação de produtos químicos pour on a cada 35 dias, iniciando-se nos meses de setembro e outubro (inicio da época das águas), bem como a rotação de princípio ativo quando necessário, realizado apenas quando um determinado principio ativo já não está tendo o efeito esperado sobre as populações de carrapatos. Essa avaliação deverá ser feita através do biocarrapaticidograma, que testa a sensibilidade dos carrapatos a determinados carrapaticidas e é uma ferramenta importante para escolha do principio ativo mais adequado para cada situação, evitando assim maiores prejuízos e surgimento de mais ácaros resistentes a determinados princípios ativos em cada local especificamente.

\section{REFERÊNCIAS}

BAFFI, M. A. Esterases e resistência a acaricidas no carrapato bovino Boophilus microplus (Acari, Ixodidae). 2006. 113f. Tese (Doutorado em Genética e Bioquímica - Área de Genética). Universidade Federal de Uberlândia. .

BLAGBURN, B. L.; LINDSAY, D. S. Ectoparasiticidas. In: ADAMS, H. R. Farmacologia e terapêutica em veterinária. 8. Ed. Rio de Janeiro: Guanabara Koogan, Cap. 50, p. 851-870, 2003. 
BRITO, L. G.et al. Eficácia de carrapaticidas em rebanhos leiteiros de Rondônia. Porto Velho (RO): Embrapa Rondônia. 4p., 2010. (Circular Técnica 113).

\section{CARVALHO NETA, A. V.; COSTA JÚNIOR, L. M. Carrapatos dos bovinos (Boophilus}

microplus) e resistência a carrapaticidas. Disponível em: endereço

$<$ http://www.beefpoint.com.br/radares-tecnicos/sanidade/carrapato-dos-bovinos-boophilus-

microplus-e-resistencia-a-carrapaticidas-34131/>. Acessado em: 18 maio 2013

CHEN, A. C.et al. A Survey of Rhipicephalus microplus Populations for Mutations Associated With Pyrethroid Resistance. J. Econ. Entomol., Columbia, v. 102, n. 1, p.373-380, 2009.

COLE, L. M.; NICHOLSON, R. A.; CASIDA, J. E. Action of phenylpyrazole insecticides at the GABA-gated chloride channel. Pestic Biochem Physiol., v. 46, p. 47-54, 1993.

COLLINS, H. L; CALLCOTT, A. M. A. Fipronil: an ultra-low-dose bait toxicant for control of red imported fire ants (Hymenoptera: Formicidae). Florida Entomologist, v. 81, n. 3, p. 407415, 1998.

CRAMPTON, A. L.et al. Monooxygenases play only a minor role in resistance to synthetic pyrethroids in the cattle tick, Boophilus microplus. Exp. Appl. Acarol., v. 23, n. 11, p. 897-905, 1999.

FAO (Food and Agriculture organization). Resistance Management and Integrated Parasite Control in Ruminants - Guidelines, Module 1 - Ticks: Acaricide Resistance: Diagnosis, Management and Prevent. Rome: Food and Agriculture Organization, Animal Production and Health Division, p. 53, 2004.

FOIL, L. D.et al. Factors that influence the prevalence of acaricide resistance and tick-borne diseases. Vet. Par., Amsterdam, v. 125, p. 163-181, 2004.

FRAGOSO-SANCHEZ, H.et al. Response of Mexican Rhipicephalus (Boophilus) microplus ticks to selection by amitraz and genetic analysis of attained resistance. J Entomol., v. 8, n. 3, p. 218-228, 2011.

FURLONG, J.; MARTINS, J. R. S. Resistência dos carrapatos aos carrapaticidas. Embrapa Gado de Leite. Juiz de Fora (MG), 25 p., 2000. (Circular técnica 59).

FURLONG, J.; PRATA, M. Resistência dos carrapatos aos carrapaticidas. 2.ed. Juiz de Fora (MG): Embrapa Gado de Leite, 2006. (Instrução técnica para o produtor de leite)

GONZALES, R. A.et al. Therapautic and persistant efficacy of doramectin against Boophilus microplus in cattle. Vet. Parasitol., Amsterdam, v.49, p.107-119, 1993.

GUERREIRO, F. D.; LOVIS, L.; MARTINS, J. R. Acaricide resistance mechanisms in Rhipicephalus (Boophilus) microplus. Rev. Bras. Parasitol. Vet., Jaboticabal, v. 21, n. 1, p. 1-6, 2012.

HE, H.et al. Sequence analysis of the knockdown resistance-homologous regions ot the para-type sodium channel gene from pyrethroid-resistance Boophilus microplus (Acari: Ixodidae). J. Med. Entomol., Columbia, v.36, n.5, p.539-543, 1999. 
KLAFKE, G. M. Resistência de R. (B.) microplus contra os carrapaticidas. In: PEREIRA, M. de C.et al. Rhipicephalus (Boophilus) microplus - Biologia, Controle e Resistência. São Paulo: MedVet., Cap. 6, p. 81-105, 2008.

LI, A. Y.et al. Resistance to coumaphos and diazinon in Boophilus microplus (Acari: Ixodidae) and evidence for the involvement of an oxidative detoxification mechanism. J. Med. Entomol., Columbia, v.40, n.4, p.482-490, 2003.

LI, A. Y.et al. Detection and Characterization of Amitraz Resistance in the Southern Cattle Tick, Boophilus microplus (Acari: Ixodidae). J. Med. Entomol., Columbia, v. 41, n. 2, p. 193-200, 2004.

LI, A. Y.et al. Genetics and Mechanisms of Permethrin Resistance in the Santa Luiza Strain of Boophilus microplus (Acari: Ixodidae). J. Med. Entomol., Columbia, v. 45, n. 3, p. 427-438, 2008.

MARQUES, A. O.; ARANTES, G. J.; SILVA, C. R. Avaliação da eficácia da ivermectina a 1\% (solução injetável), no tratamento de bovinos naturalmente infestados pelo carrapato Boophilus microplus (CANESTRINI, 1887) (ACARI:IXODIDAE) e mantidos em pastagem. Rev. Bras. Parasitol. Vet., Jaboticabal, v.4, n.2, p.117-119, 1995.

MARTINS, J. R. Manejo da resistência aos carrapaticidas. Rev. Bras. Parasitol. Vet., Jaboticabal, v. 13, supl. 1, p. 114-115, 2004.

MENDES, M. C.; LIMA, C. K. P.; PRADO, Â. P. do. Determinação da frequiência de realização de bioensaios para o monitoramento da resistência do carrapato Boophilus microplus (Acari: Ixodidae). Arq. Inst. Biol., São Paulo, v. 74, n. 2, p. 87-93, 2007.

MENDES, M. C.; PINTO LIMA, C. K.; PEREIRA, J. R. Práticas de manejo para o controle de o carrapato Rhipicephalus (Boophilus) microplus (Acari: Ixodidae) em propriedades localizadas na região de Pindamonhangaba, Vale do Paraíba, São Paulo. Arq. Inst. Biol., São Paulo, v. 75, n. 3, p. 371-373, 2008.

MERLINI, L. S.; YAMAMURA, M. H. A resistência do Boophilus microplus Canestrini, 1887 aos produtos químicos. Arq. Ciênc. Vet. Zool., Umuarama, v. 2, n. 1, p. 53-59, 1999.

MILLER, R. J.; DAVEY, R. B.; GEORGE, J. E. Characterization of pyrethroid resistance and susceptibility to coumaphos in Mexican Boophilus microplus (Acari: Ixodidae). J. Med.

Entomol., Columbia, v.36, n.5, p. 533-538, 1999.

NETO, S. F. P.; TOLEDO-PINTO, E. A. Análise da eficiência dos carrapaticidas contra Boophilus microplus em gado leiteiro. Revista científica eletrônica de medicina veterinária, Garça, v. 3, n. 7, 7 p., 2006.

RAUH, J. J.; LUMMIS, S. C. R.; SATTELLE, D. B. Pharmacological and biochemical properties of insect GABA receptors. TiPS, Cambridge v. 11, p. 325-329, 1990.

ROCHA, C. M. B. M. da et al. Percepção dos produtores de leite do município de Passos, MG, sobre o carrapato Boophilus microplus (Acari: Ixodidae), 2001. Ciência Rural, Santa Maria, v.36, n.4, p.1235-1242, 2006. 
SARTOR, I. F.; BICUDO, P. L. Agentes empregados no controle de ectoparasitas. In: SPINOSA, H. de S. et al. Farmacologia aplicada à Medicina Veterinária. 2.ed. Rio de Janeiro: Guanabara Koogan, 1999. Cap. 47, p. 480-492.

SOUTELlO, R. V. G.et al. Seleção de bovinos de corte resistentes ao carrapato. Ciên. Agr. Saúde, Andradina v. 2, n. 2, p 57-60, 2002.

VILLARINO, M. A.; WAGHELA, S. D.; WAGNER, G. G. Histochemical Localization of Esterases in the Integument of the Female Boophilus microplus (Acari: Ixodidae) Tick. J. Med. Entomol., Columbia, v. 38, n. 6, p. 780-782, 2001.

WHARTON, R. H.; ROULSTON, W. J. Acaricide resistance in Boophilus microplus in Austrália. In: WORKSHOP ON HEMOPARASITES (ANAPLASMOSIS AND BABESIOSIS), 1975, Cali, Colombia. Proceedings... Bogotá: Centro Internacional de Agricultura Tropical, v.2. p. 73-92, 1977.

ZHAO, X.et al. Fipronil is a potent open channel blocker of glutamate-activated chloride channels in cockroach neurons. J Pharmacol Exp Ther., Bethesda, v. 310, p. 192-201, 2004 